19. Кочетова Т.Н. Современные технологии математической подготовки будущего инженера // Вестник Самарского государственного технического университета. Серия: Психолого-педагогические науки. 2014. № 2 (22). С. 102-107.

20. Стельмах Я.Г. Формирование профессиональной математической компетентности студентов - будущих инженеров: автореф. дис. .... канд. пед. наук.
Самарская государственная социально-гуманитарная академия. Самара, 2011.21 с.

21. Стельмах Я.Г. Активизация исследовательской деятельности студентов при изучении математики // Вестник Самарского государственного технического университета. Серия: Психолого-педагогические науки. 2014. № 1 (21). С. 166-173.

\title{
SPECIAL ASPECTS OF ACADEMIC BACHELORS' MATHEMATICAL TRAINING
} (C) 2016

Y.G. Stelmah, candidate of pedagogical sciences, assistant professor of the Chair of Higher Mathematics and Applied Informatics

Samara State Technical University, Samara (Russia)

Abstract. The analysis of federal state educational standards of higher education (FSES) allowed to identify the research activity and different kinds of project activities (design and project ones) as one of the basic standards for academic bachelor programmes of various courses. A graduate that has mastered this programme should be ready to meet the professional challenges demanding from him specific knowledge and skills in different fields, including Mathematics and he should obtain them while studying at university. Specific aspects of academic bachelors' mathematical training should be taken into consideration in terms of academic activities. In this article we interpret the aspects of academic bachelors' mathematical training as the academic activities based on personalizing the academic studies and implying an efficient combination of teaching ready to learn knowledge and the ways of its obtaining while solving the goals corresponding in their structures to the types of professional activities. At the same time we consider the personalizing of the academic studies as the process of projecting their own studies by the students themselves. The carried out analysis of scientific literature, of kinds of professional activity and of Mathematics activities allowed to specify the following features of bachelors' mathematical training: Mathematics is a research tool for most sciences and for facing professional challenges; an academic potential is expressed in mindset formation; there is a high level of fundamentalization of mathematic operations while facing future professional goals.

Keywords: higher education; professional goals; academic bachelors; project activity; an academic potential; a research activity; Mathematics; challenges; project; analysis; mathematical training; an activity approach.

\section{УДК 378}

\section{К ВОПРОСУ О ФОРМИРОВАНИИ МЕТАПРЕДМЕТНЫХ КОМПЕТЕНЦИЙ У БУДУЩИХ БАКАЛАВРОВ И СПЕЦИАЛИСТОВ}

(C) 2016

Н.А. Тимощук, кандидат филологических наук, доцент, заведующий кафедрой психологии и педагогики Самарский государственный технический университет, Самара (Россия)

Аннотащия. Федеральный государственный образовательный стандарт основного общего образования устанавливает требования к личностным, метапредметным и предметным результатам освоения обучающимися основной образовательной программы основного общего образования. Следовательно, в соответствии с принципом преемственности при обучении необходимо развивать и формировать у студентов компетенции по указанным трём направлениям, трансформируя их в образовательное пространство вуза. В частности, метапредметные компетенции должны включать в себя способность оперировать межпредметными понятиями и универсальными учебными действиями, используя их в учебной, познавательной и социальной практике. Достижение метапредметных результатов связано с природой универсальных учебных действий. В основу природосообразного образования личности должны быть положены базисные ценности - это, прежде всего, нравственность, следующая из природы самого человека. Именно поэтому в стандартах второго поколения выделяют уже четыре блока универсальных учебных действий: личностных, регулятивных, общепознавательных и коммуникативных. В силу своей природы, являясь, по сути, функционально-ориентировочными действиями, метапредметные действия составляют психологическую основу и решающее условие успешности решения обучающимися предметных задач. Формирование у студентов метапредметных компетенций предполагает различные формы организации учебного процесса. Проблемное обучения подразумевает активное взаимодействие субъектов образовательного процесса, что позволяет формировать у студентов такие категории, как «готовность», «активность», «способность оценить», являющиеся ключевыми для термина «компетенция». Одной из организационных форм занятий является деловая игра, которая может использоваться как средство диагностики и прогнозирования поведения личности в различных ситуациях. Проектная технология ориентирована на развитие широкого спектра компетенций и творческих способностей, поэтому предполагает интегра- 
Тимощук Н.А.

К вопросу о формировании метапредметных компетенций.

13.00 .00 - педагогические науки

цию исследовательских, поисковых, проблемных, сравнительных методов. Показано, что в настоящее время радикально увеличивается роль каждой дисциплины в развитии метапредметной компетентности личности.

Ключевые слова: метапредметные компетенции; универсальные учебные действия; метапредметные результаты; познавательная деятельность; регулятивная деятельность; коммуникативная деятельность; функционально-ориентировочные действия; мировоззренческие математические понятия; речевая культура.

Федеральный государственный образовательный стандарт основного общего образования (ФГОС ООО), утверждённый приказом Министерства образования и науки Российской Федерации от 17 декабря 2010 г. № 1897, представляет собой совокупность требований, обязательных при реализации основной образовательной программы основного общего образования образовательными учреждениями, имеющими государственную аккредитацию [1]. Стандарт устанавливает требования к личностным, метапредметным и предметным результатам освоения обучающимися основной образовательной программы основного общего образования.

В соответствии с принципом преемственности, в университете необходимо развивать формирование компетенций по указанным трём направлениям, трансформируя их к образовательному пространству вуза $[2 ; 3]$.

Остановимся более подробно на метапредметных компетенциях. Они должны включать в себя способность оперировать межпредметными понятиями и универсальными учебными действиями, используя их в учебной, познавательной и социальной практике $[4 ; 5]$.

В научных публикациях, посвященных метапредметному подходу в образовании, нет однозначного толкования понятия «метапредметные компетенции». А.В. Хуторской [6; 7] считает, что метапредметные компетенции обеспечивают реализацию основных универсальных учебных действий (УУД): регулятивных, коммуникативных, познавательных. Все ключевые компетенции определяют регулятивные учебные действия. Коммуникативные УД служат установлению правильных взаимоотношений с обучаемыми, обеспечивают эффективность педагогического общения. Познавательные УД характеризуют освоение знаний и способов их применения в целях познания и лучшего понимания реалий окружающей действительности. Все они являются способами деятельности, которые осваиваются обучающимися на базе одного, нескольких или всех учебных предметов и которые могут быть применены как в рамках образовательного процесса, так и при решении проблем в реальных жизненных ситуациях. Согласно А.В. Хуторскому, цель образования - не освоение учебной деятельности, а именно генерация, продуцирование образовательного результата, имеющего ценность не только для обучаемого, но и для окружающего его социума, мира, человечества.

Достижение метапредметных результатов связано с природой универсальных учебных действий. В основу природосообразного образования личности должны быть положены базисные ценности - это, прежде всего, нравственность, следующая из природы самого человека. Именно поэтому в стандартах второго поколения выделяют уже четыре блока УУд: личностных, регулятивных, общепознавательных и коммуникативных. В силу своей природы, являясь, по сути, функционально-ориентировочными действиями, метапредметные действия составляют психологическую основу и решающее условие успешности решения обучающимися предметных задач [8-10].

Метапредметные результаты предполагают освоение студентами универсальных способов деятельности или универсальных учебных действий, применимых как в рамках образовательного процесса, так и в реальных жизненных ситуациях. Овладение системой универсальных учебных действий является необходимой основой всего последующего развития индивидуума. Это действия, обеспечивающие самостоятельную, субъектную позицию обучаемого в ходе его образования в течение всей жизни.

Метапредметные результаты включают освоенные обучающимися межпредметные понятия и универсальные учебные действия (регулятивные, познавательные, коммуникативные), способность их использования в учебной, познавательной и социальной практике, самостоятельность планирования и осуществления учебной деятельности и организации учебного сотрудничества с педагогами и сверстниками, построение индивидуальной образовательной траектории. Метапредметные результаты освоения основной образовательной программы основного общего образования должны отражать:

1) умение самостоятельно определять цели своего обучения, ставить и формулировать для себя новые задачи в учёбе и познавательной деятельности, развивать мотивы и интересы своей познавательной деятельности;

2) умение самостоятельно планировать пути достижения целей, в том числе альтернативные, осознанно выбирать наиболее эффективные способы решения учебных и познавательных задач;

3) умение соотносить свои действия с планируемыми результатами, осуществлять контроль своей деятельности в процессе достижения результата, определять способы действий в рамках предложенных условий и требований, корректировать свои действия в соответствии с изменяющейся ситуацией;

4) умение оценивать правильность выполнения учебной задачи, собственные возможности её решения;

5) владение основами самоконтроля, самооценки, принятия решений и осуществления осознанного выбора в учебной и познавательной деятельности;

6) умение определять понятия, создавать обобщения, устанавливать аналогии, классифицировать, самостоятельно выбирать основания и критерии для классификации, устанавливать причинно-следственные связи, строить логическое рассуждение, умозаключение (индуктивное, дедуктивное и по аналогии) и делать выводы;

7) умение создавать, применять и преобразовывать знаки и символы, модели и схемы для решения учебных и познавательных задач;

8) смысловое чтение; 
9) умение организовывать учебное сотрудничество и совместную деятельность с учителем и сверстниками; работать индивидуально и в группе: находить общее решение и разрешать конфликты на основе согласования позиций и учёта интересов; формулировать, аргументировать и отстаивать своё мнение;

10) умение осознанно использовать речевые средства в соответствии с задачей коммуникации для выражения своих чувств, мыслей и потребностей; планирования и регуляции своей деятельности; владение устной и письменной речью, монологической контекстной речью;

11) формирование и развитие компетентности в области использования информационно-коммуникационных технологий (далее ИКТ-компетенции);

12) формирование и развитие экологического мышления, умение применять его в познавательной, коммуникативной, социальной практике и профессиональной ориентации.

Формирование у студентов метапредметных компетенций предполагает различные формы организации учебного процесса. При обучении дисциплинам гуманитарного цикла целесообразно использовать современные педагогические технологии. Анализ научной литературы позволяет выделить наиболее значимые характеристики и признаки, указывающие на то, что педагогическая технология:

- предполагает продуктивное взаимодействие субъектов учебного процесса с целью достижения высокой результативности обучения;

- представляет совокупность форм, методов, способов, приемов и средств, обеспечивающих эффективность достижения целей обучения;

- предусматривает объективный контроль, диагностику и коррекцию учебного процесса [11].

Основной дидактической задачей является эффективное сочетание педагогических технологий в процессе обучения гуманитарным дисциплинам, которые содействуют активизации учебно-познавательной деятельности студентов. Важным является использование технологии проблемного обучения, которое «направлено на формирование навыков и умений самостоятельной познавательной деятельности студентов, на развитие их логического, рационального, критического и творческого мышления и познавательных способностей» [12]. Технология проблемного обучения позволяет приобщиться к объективным противоречиям науки, социальной и профессиональной практики и способам их разрешения, учиться мыслить, творчески усваивать знания. Проблемное обучения подразумевает активное взаимодействие субъектов образовательного процесса с проблемно представленным содержанием обучения, что позволяет формировать у студентов такие категории, как «готовность», «активность», «способность оценить», являющиеся ключевыми для термина «компетенция». В диалогическом проблемном обучении студент не просто перерабатывает и усваивает сообщаемую ему информацию, он переживает процесс познания как субъективное открытие еще неизвестного ему знания, как личностную ценность, обусловливающую развитие мотивации, интереса к содержанию учебного предмета (ценностная составляющая компетенций) [13].
Основными целями проблемной лекции, указывает А.А. Вербицкий [14] является:

- усвоение слушателями теоретических знаний;

- развитие теоретического мышления;

- формирование познавательной и профессиональной мотивации;

- создание возможностей исследовательского отношения к содержанию научного знания.

Педагогический опыт показывает, что метод решения проблем целесообразно применять в преподавании курса «Деловое общение и культура речи». При изучении раздела «Работа над текстом публичного выступления» преподаватель, например, ставит проблему: как построить успешное публичное выступление? Возможно построение лекции разными способами:

- решение проблемы самим лектором в диалоге со студентами;

- решении проблемы студентами в диалогическом общении и межличностном контакте;

- формулирование проблемы самими студентами и решение ее при консультативной поддержке преподавателя.

Таким образом, в ходе решения проблемы студенты расширяют свои знания, умение выстраивать логически грамотную, аргументированную устную речь, развивают коммуникативные, метапредметные компетенции.

Одной из организационных форм занятий является деловая игра, которая может использоваться как средство диагностики и прогнозирования поведения личности в различных ситуациях. Например, на практических занятиях по деловым коммуникациям, при изучении темы «Деловая беседа» со студентами проводится деловая игра «Собеседование» (приём на работу). Обучающиеся конструируют встречу с потенциальным работодателем, обдумывают различные варианты и отдельные детали разговора, планируют диалог, направленный на достижение успеха. Затем всей группой проводится обсуждение типичных ошибок соискателя и возможностей реального устройства на работу.

В процессе игры студенты учатся анализировать и прогнозировать ситуации, самостоятельно принимать решения, проявлять личностные качества. Такая форма обучения способствует формированию социально-критического мышления (когнитивный компонент), позитивной моральной самооценки и моральных чувств (ценностно-эмоциональный компонент), умению вести диалог на основе равноправных отношений и взаимного уважения (деятельностный компонент) и пониманию важности приобретения навыков самопрезентации и их успешной демонстрации.

Важной составляющей учебного процесса становится проектная технология, которая «ориентирована на развитие широкого спектра компетенций и творческих способностей, поэтому предполагает интеграцию исследовательских, поисковых, проблемных, сравнительных методов. Создание учебного проекта предполагает решение ряда взаимосвязанных задач, как правило, межпредметного характера. Задача преподавателя состоит в том, чтобы: 
- сформировать у студентов осознанную потребность, интерес к содержанию проблемы и выполнению проектной деятельности;

- убедить в значимости овладения научноисследовательскими методами, которые они смогут применять не только в ходе дальнейшего обучения специальным дисциплинам, но и в будущей профессиональной деятельности;

- обеспечить методическими рекомендациями по выполнению проекта сообразно поставленным целям, задачам, требованиям по содержанию и оформлению проекта» [11].

Например, в курсе «Риторика» при изучении темы «Речевой этикет и культура общения» предлагается разработать проект, формой представления результата которого является презентация и создание буклета национальных особенностей речевых этикетных формул делового общения (например, европейской и китайской культур). В процессе проектирования развиваются метапредметные способности: способности исследовательской, творческой, коммуникативной, информационной деятельности, рефлексия, аналитическое мышление, поликультурная компетентность.

Из вышесказанного следует, что метапредметную компетентность можно представить как интегративную дефиницию, основными компонентами которой являются ценностно-личностный, регулятивный, коммуникативный и познавательный. Из представленных компонентов можно выделить общий для всех ценностный или мировоззренческий компонент, являющийся основой каждой из них. К сожалению, реальность свидетельствует о том, что в настоящее время практически во всех сторонах социальной и культурной деятельности человека в его сознании прочно утвердилось представление об исключительности только своего социума и освобождённости его от подчинения метапредметным закономерностям, что объясняется недостаточной мировоззренческой подготовкой. Именно поэтому наполняемость этого понятия ценностно-личностной составляющей необходима.

Важно отметить, что сегодня радикально увеличивается роль каждой дисциплины в развитии метапредметной компетентности личности. В частности, усиливается значение геометрических компетентностей в формировании ценностно-смысловых, общекультурных, учебно-познавательных, информационных и других составляющих мировоззренческого компонента метапредметной компетентности $[15 ; 16]$.

Приведем другие примеры возможностей математической науки [17]. Одним из первичных мировоззренческих неопределяемых математических понятий является понятие множества, описательное объяснение которого - совокупность, объединение объектов любой природы, называемых элементами множества (это могут быть числа, функции, явления природы, предметы, вещи и т.п.). Именно поэтому теория множеств имеет самое широкое приложение. Мировоззренческий компонент метапредметной компетентности можно интерпретировать как некоторое множество $U$, состоящее из бесконечного числа элементов и, следовательно, являющееся бесконечным множеством. Множество $M$ называется подмножеством множества $U$, если каждый элемент множества
$M$ принадлежит множеству $U$ (рис. 1). Обозначают М $\subset \mathrm{U}$ и говорят, что « $M$ - подмножество $U »$ или « $M$ включается в $U$ ». Множества, подмножества и отношения между ними принято иллюстрировать геометрически с помощью диаграмм (кругов) ЭйлераВенна. Точки внутри фигуры считаются элементами множества.

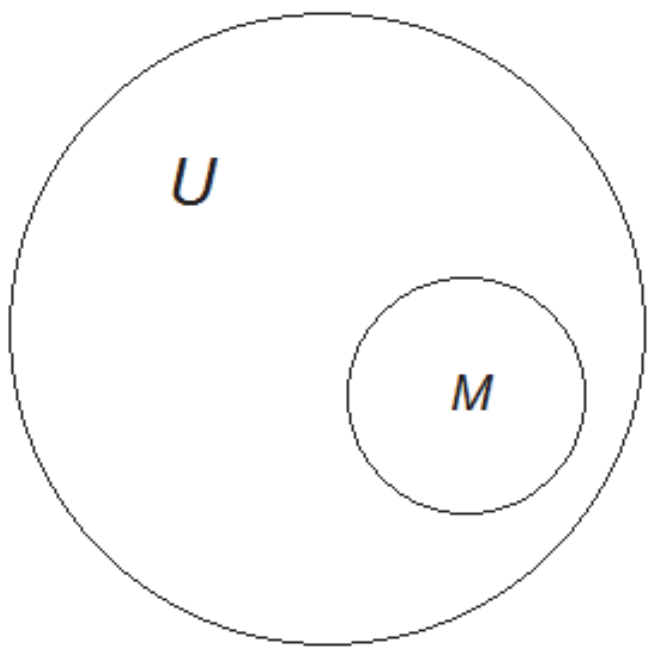

Рисунок 1 - Интерпретация

математической составляющей М в общей мировоззренческой подготовке U

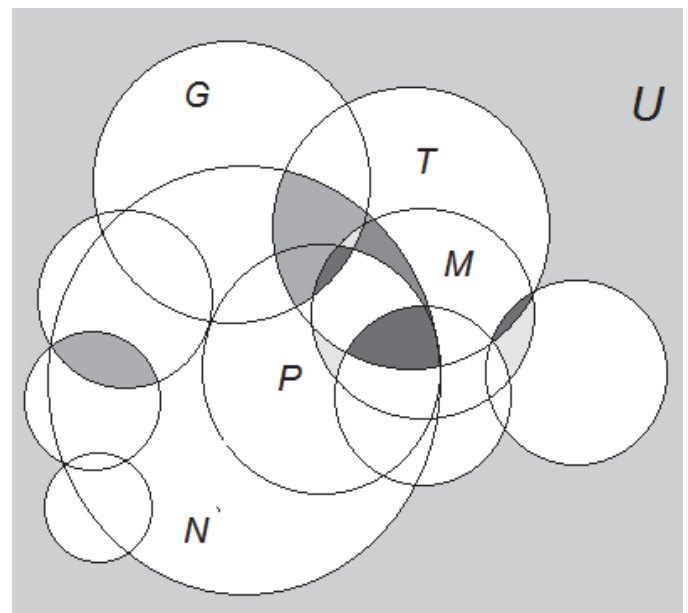

Рисунок 2 - Интерпретация взаимодействия различных составляющих

Составляющую мировоззренческой подготовки $\mathrm{M}$, формируемую при изучении математики, закономерно считать подмножеством множества U. Подмножествами U можно считать и другие составляющие мировоззренческой подготовки. К ним можно отнести гуманитарную $\mathrm{G}$, научную $\mathrm{N}$, техническую T, прикладного характера Р, бытовую В и другие составляющие. Эти подмножества могут объединяться и пересекаться причудливым образом, образуя новое интегрированное знание (рис. 2). Множество, относительно которого все множества, рассматриваемые в задаче, являются подмножествами, называется универсальным. В рассматриваемом случае универсальным является множество U, соответствующее мировоззренческому компоненту метапредметной компетентности. Его принято обозначать буквами U или I и изображать в виде прямоугольника на диаграммах Эйлера-Венна. 
Не менее интересным мировоззренческим понятием математики являются функции (от лат. function - исполнение, совершение). Функция может рассматриваться с точки зрения следствий в объекте (благоприятных, неблагоприятных или дисфункциональных, а также нейтральных или афункциональных), вызываемых изменением одного или нескольких параметров. В данном случае рассматривается функциональность объекта, позволяющая определять взаимообусловленность компонентов метапредметной компетентности. Использование теории векторов способствует определению стратегий дальнейшего развития. К таковым стоит отнести следующие: изменения в содержании понятия, в содержании процесса формирования, разработки критериев оценки метапредметной компетентности.

Одной из важнейших задач метапредметной подготовки является формирование вербальных компетенций будущих инженеров, что приводит к необходимости разработки теории и методики системы развития речевой культуры студентов в процессе изучения блоков общеобразовательных и специальных дисциплин [18]. Требуется проектирование и разработка новых технологий обучения, включающих в себя дополнительные формы и методы проведения лабораторных работ, деловых игр, семинаров, написания самостоятельных заданий в виде эссе, пояснительных записок и т.д.

Обобщая изложенное выше, полагаем, что введение в образовательную практику упражнений, разработанных на основе междисциплинарного подхода, позволит расширить кругозор личности студента, развить аналитические умения, способности обобщать и мыслить интегративно, что является основой для успешного формирования метапредметнной компетентности.

\section{СПИСОК ЛИТЕРАТУРЫ:}

1. Закон Российской Федерации «Об образовании» (Ведомости народных депутатов Российской Федерации и Верховного Совета Российской Федерации, 1992. № 30, ст. 1797; Собрание законодательства Российской Федерации, 1996. № 3, ст. 150; 2007. № 49, ст. 6070 .

2. Тимощук Н.А. Преемственность в реализации федеральных государственных образовательных стандартов // Математическое образование: прошлое, настоящее и будущее: Материалы IV Всероссийской III Международной заочной научно-практической конференции, посвящённой 100-летию со дня рождения К.А. Малыгина. Самара, 1-2 декабря 2015 г. Самара: ПГСГА, 2015.

3. Тимощук Н.А. Формирование метапредметной компетентности у студентов технического университета // Вестник Самарского государственного технического университета. Серия «Психолого-педагогические науки». 2015. № 3. С. 233-241.

4. Бейлина Н.С., Тимощук Н.А., Чеканушкина Е.Н. Формирование социальной компетентности студентов в современном вузе: учеб. пособие. Самара: Самар. гос. техн. ун-т, 2015. 136 с.

5. Тимощук Н.А. Инновационный подход в оценивании учебной деятельности // Новая стратегия оценивания учебной деятельности: Материалы Международной научно-методической конференции. Самара, 17 февраля 2016 г. Самара: СГАСУ, 2016.

6. Хуторской А.В. Метапредметное содержание и результаты образования: как реализовать федеральные государственные образовательные стандарты (ФГОС) [Электронный pecypc] // http://eidos.ru/ journal/2012/0229-10.htm.

7. Хуторской А.В. Нынешние стандарты нужно менять, наполнять их метапредметным содержанием образования // Народное образование. 2013. № 4. C. $157-171$.

8. Санникова А.И., Крузе Б.А. Определение понятия лингвомультимедийной компетентности будущего учителя иностранного языка // Педагогическое образование и наука. 2010. № 9. С. 51-55.

9. Санникова А.И., Крузе Б.А. Подготовка полилингвальной и поликультурной личности учителя международного бакалавриата: мультимедийно опосредованный контекст // Педагогическое образование и наука. 2010. № 9. С. 75-78.

10. Формирование универсальных учебных действий в основной школе: от действия к мысли. Система заданий: пособие для учителя / А.Г. Асмолов и др.; под ред. А.Г. Асмолова. 2-е изд. М.: Просвещение, 2011. 159 с.

11. Чеканушкина Е.Н. Формирование социальноэкологической компетентности у студентов технического университета в процессе их обучения гуманитарным, социально-экономическим и естественнонаучным дисциплинам: дис. ... канд. пед. наук. Самара, 2011. 179 c.

12. Михелькевич В.Н., Охтя Н.В., Сухинин В.П. Проектирование и анализ педагогических технологий: Лаб. практикум. Самара: СамГТУ, 2006. 44 с.

13. Гуреева Е.Г. Технология формирования экологической компетентности инженеров общественного питания // Вестник Самарского государственного технического университета. Серия «Психолого-педагогические науки». № 2 (10). Самара: Изд-во СамГТУ, 2008. С. 62.

14. Вербицкий А.А. Педагогические технологии контекстного обучения: научно-методическое пособие. М.: РИЦ МГТУ им. М.А. Шолохова, 2011. 52 с.

15. Рябинова Е.Н., Мазуренко Е.В. Преемственность в формировании геометрических компетенций при изучении математики в вузе // Вестник Самарского государственного технического университета. Серия: Психолого-педагогические науки. 2014. № 4 (24). С. 171-178.

16. Рябинова Е.Н., Рудина Т.В. Формирование геометрических компетенций при решении задач по теме «Прямая и плоскость» // Сборник трудов III Международной научной конференции «Геометрия и геометрическое образование в современной средней и высшей школе». Тольятти : ТГУ, 2014. С. 289-293.

17. Рябинова Е.Н., Жукова Т.А., Мазуренко Е.В. Роль математики в формировании мультикультурной компетентности студентов высшей профессиональной школы // Сборник трудов VII Международной научной конференции «Математика. Образование. Культура». Тольятти : ТГУ, 2015. С. 50-52. 
18. Рябинова Е.Н., Марченкова Л.А. К вопросу об актуальности формирования вербальных компетенций студентов технических вузов // Вестник Самар-

ского государственного технического университета. Серия «Психолого-педагогические науки». 2015. № 2 (26). С. 163-170.

\section{META-SUBJECT COMPETENCE DEVELOPMENT OF FUTURE BACHELORS AND SPECIALISTS}

N.A. Timoschuk, candidate of philological sciences, head of the Chair of Psychology and Pedagogy Samara State Technical University, Samara (Russia)

Abstract. Federal State Educational Standard of basic common education sets the demands to personal, metasubject and subject results of learning after basic educational program of common education. So, according to the succession principle we should develop the competence of the students following these three directions transforming them into educational environment of the university. Thus, meta-subject competence should include ability to use intersubject definitions and universal learning activities performing them at learning, knowledge and social practice. The achievement of meta-subject results is connected with the nature of universal activity. The basis of nature-coordinated education should be basic values - and the most important is morality which is formed from the human nature. That is why the standards of the second generation formulate four blocks of universal learning activities: personal, regulative, common knowledge and communicative. According to their nature meta-subject activities are functional-oriented ones and they form the psychological basis and determine condition of the success of subject task solution. Meta-subject competence development supposes various forms of studying process organization. Problem learning implies active interrelation of the subjects of learning process allowing to form such students' categories as «readiness», «activeness», «ability to appreciate» which are the key ones for the term «competence». One of such organization forms can be the business game which can be used as the means of diagnosis and forecast of personal behavior in various situations. Project technology is also aimed to develop wide range of competence and creative abilities and that is why it suggests the integrity of research, searching, problem solving and comparison methods. It has been shown that nowadays the role of each discipline in meta-subject competence development has been growing rapidly.

Keywords: meta-subject competence; universal learning activity; meta-subject results; knowledge activity; regulative activity; communicative activity; functional-oriented actions; world outlook mathematical definitions; speech culture. 